\title{
Drought Tolerance among Accessions of Eggplant and Related Species
}

\author{
Ana FITA*, Fabrizio FIORUCI, Mariola PLAZAS, Adrián RODRIGUEZ-BURRUEZO, Jaime PROHENS \\ Instituto de Conservación y Mejora de la Agrodiversidad Valenciana. Universitat Politècnica de \\ Valencia, Spain. \\ *)corresponding author, e-mail: anfifer@btc.upv.es
}

BulletinUASVM Horticulture 72(2) / 2015

Print ISSN 1843-5254, Electronic ISSN 1843-5394

DOI:10.15835/buasvmcn-hort:11600

\begin{abstract}
Adapting eggplant (Solanum melongena) cultivars to climate change requires the development of drought tolerant cultivars. In order to identify sources of variation for drought tolerance we have characterized nine accessions of eggplant and six of related species for tolerance to drought using a control with optimum irrigation and a drought treatment with a 50\% reduction of irrigation. Many differences were found in the materials studied for the four parameters measured (leaf length and width, plant height and dry biomass). The materials with better performance have been S. elaeagnifolium and one accession of eggplant, while the most discriminant traits have been plant height and dry biomass. Overall, the results indicate that there is a large diversity in the germplasm of eggplant and related species for tolerance to drought.
\end{abstract}

Keywords: climate change, drought, phenotyping, roots, Solanum spp.

\section{Introduction}

Eggplant (Solanum melongena L.) is a widespread horticultural species in temperate and tropical areas around the world. Given the challenges posed by climate change it is necessary to develop cultivars of this vegetable adapted to drought. Some eggplant relatives grow in desertic and dry areas (Knapp et al., 2013), and may be of interest for breeding for tolerance to drought. The development of cultivars or even rootstocks tolerant to drought in eggplant depends on: i) identification of germplasm of interest, and ii) introgression of genes from this germplasm into eggplant lines (Cattivelli et al., 2008). Both activities require quick, cheap and effective assessment of drought tolerance, if possible in young plants.

\section{Aims}

The objective of this study was: i) to screen a collection of 15 accessions of eggplant and related species for tolerance to drought, and ii) develop an appropriate high throughput phenotyping system in young plants feasible to evaluate large populations.

\section{Materials and Methods}

The plant material used was: nine accessions of cultivated S. melongena (ANS26, CS16, G.B., H15, J.S., K, L. Gandía, L.F., and MEL2) from diverse backgrounds, and five of related species: two accessions of $S$. aethiopicum (AET1 and AET2), one of $S$. anguivi (ANG1), one of $S$. elaeagnifolium (ELE2), one of $S$. linnaeanum (LIN1), and one of $S$. macrocarpon (MAC1). Plants were grown under 

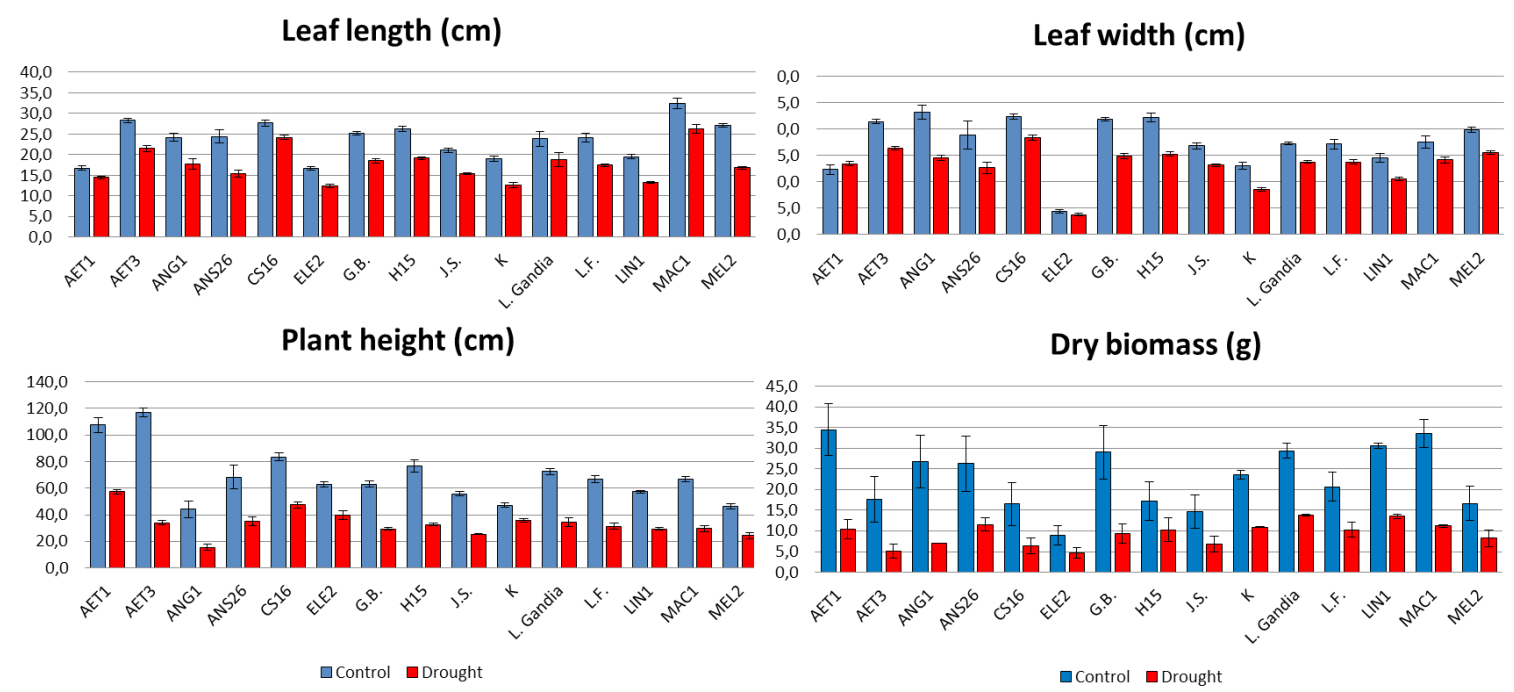

Fig. 1. Parameters evaluated in plants grown under control and drought conditions. Each column is the average of 10 plants $( \pm$ SE).

two different treatments: i) control with optimum irrigation, and ii) drought treatment where irrigation was reduced by $50 \%$ with respect to the control. The measurements were divided into nondestructive (plant height, leaf size as leaf length) and destructive (biomass) measurements.

\section{Results}

The results showed an important diversity within cultivated eggplant for tolerance to drought (Fig 1). Interestingly, not all relatives of eggplant necessarily showed a better response to drought than cultivated $S$. melongena. In fact the genotypes with best results were the wild species S. elaeagnifolium, which was very vigorous under stress, and the cultivated eggplant variety K. The different genotypes appear to have different mechanisms of drought tolerance; it may be of interest to combine these mechanisms in order to obtain new improved varieties tolerant to drought. Regarding the protocol used, the most discriminant parameters to select resistant plants were the plant height and its biomass.

\section{Conclusion}

An important diversity for tolerance to drought exists in cultivated eggplant, as well as in related species. Solanum elaeagnifolium grows in very dry environments (Christodoulakis et al., 2009) and may represent an interesting resource for breeding eggplants for tolerance to drought. For future screenings in young plants, we propose to use plant height to make a quick selection of highly susceptible genotypes, eliminate them, and subsequently make a more accurate evaluation based on biomass accumulation.

Acknowledgements. This work was completed as part of the initiative "Adapting Agriculture to Climate Change: Collecting, Protecting and Preparing Crop Wild Relatives", which is supported by the Government of Norway. The project is managed by the Global Crop Diversity Trust with the Millennium Seed Bank of the Royal Botanic Gardens, Kew and is implemented in partnership with national and international gene banks and plant breeding institutes. For further information see the project website: http://www.cwrdiversity. org/.

\section{REFERENCES}

1. Cattivelli L, Rizza F, Badeck FW, Mazzucotelli E, Mastrangelo AM, Francia E, Marè C, Tondelli A, Stanca AM (2008). Drought tolerance improvement in crop plants: an integrated view from breeding to genomics. Field Crops Res 105:1-14.

2. Christodoulakis NS, Lampri PN, Fasseas C (2009). Structural and cytochemical investigaction of the silverleaf nightshade (Solanum elaeagnifolium), a drought-resistant alien weed of the Greek flora. Austral J Bot 57:432-438.

3. Knapp S, Vorontosova M, Prohens J (2013). Wild relatives of eggplant (Solanum melongena L.: Solanaceae): New understanding of species names in a complex group. PLOS ONE 8:e57039. 